Journal of the Egyptian Society of Parasitology, Vol.43, No.2, August 2013

J. Egypt. Soc. Parasitol., 43(2), 2013: 457 - 462

\title{
PREVALENCE AND EFFECT OF A COMBINED TREATMENT ON PNEUMOCYSTITIS PNEUMONIA
}

\author{
By \\ NADA A. ELNADI ${ }^{1}$, ALZAHRAA E. ALMASRY ${ }^{2}$ \\ AND MOSTAFA M ABOSDERA ${ }^{2}$
}

Departments of Medical Parasitology ${ }^{1}$ and Pediatrics ${ }^{2}$, Faculty of Medicine, Sohag University, Sohag, Egypt

\begin{abstract}
Pneumocystitis may cause fatal pneumonia in premature, seriously ill infants at intensive care units. The present study evaluated the routine treatment applied at Sohag pediatrics department for neonatal and infantile pneumonia (in NICU \& PICU) on PCP and to compare between the stained slides and real time-PCR in diagnosing Pneumocystis jirovecii. Sucked sputum from 21 pneumonic infants was collected, some for Giemsa stain and microscopic examination and the rest for PCR. The same procedure was done after regression of the symptoms and before release from the units. Serum samples were also collected on admission and discharge for CRP readings which was also used as an indicative of the healing process. Out of 21 pneumonic neonates and infants examined, $12(57.1 \%)$ showed $P$. jirovecii in sputum samples with a significant difference between both groups $(p=0.2) .10$ of them $(83.3 \%)$ became negative for $p$. jirovecii under the routine regimen of treatment. Also 2 cases were infected with microspora, both improved at the end of treatment. While real time PCR was negative in all cases pre and post treatment. CRP levels regressed after treatment in all cases except 2 as one showed post treatment $P$. jirovecii in the sputum.
\end{abstract}

Key words: Egypt, Infants, Pneumocystis jirovecii, pneumonia, treatment, CRP, Real time PCR.

\section{Introduction}

Pneumocystis was discovered nearly a century ago. It causes fatal pneumonia in immunocompromised individuals, The organism that causes human PCP Pneumocystis pneumonia is now named $P$. jirovecii Frenkel, 1999 (Herraq et al, 2010). Premature, seriously ill infants at intensive care units constitute a potential risk group for infection (Kordek et al, 2006). Dyspnea, cough, hypoxia, and fever are the commonest symptoms of PCP (Shanker and Nania, 2007). Diagnosis was established by detecting $P$. jirovecii cysts in bronchial lavage fluid specimens, Gomori's methenamine-silver stain, Geimsa or Wright's stain, and monoclonal immuno fluorescent antibody stains are commonly used to make a diagnosis $(88.1 \%$ sensitivity). Chest radiography and highresolution chest CT scans showed a 
characteristic ground-glass pattern. Induced sputum analysis and bronchoalveolar lavage are the diagnostic procedures of choice. However, identification of $P$. jiroveci DNA using polymerase chain reaction assays in bronchoalveolar lavage fluid is more sensitive (Kordek et al, 2007; Pyrgos et al, 2009). PCP was treated by cotrimoxazole $^{\circledR}$ and pentamidine ${ }^{\circledR}$ (or trimethoprim-sulfamethoxazole (Shanker and Nania, 2007) combination therapy over 14 days (Kordek et al. (2007). Pyrgos et al. (2009) recommended pentamidine $^{\circledR}$, atovaquone ${ }^{\circledR}$, clindamycin ${ }^{\circledR}$ and primaquine, and dapsone plus trimethoprim as alternatives. All pulmonary microsporidiosis were immunodepressed patients, with clinical rhinosinusitis (Franzen, 1996), fever, persistent cough, dyspnoea and acute respiratory distress that may to death due to cardiorespiratory failure. Diagnostic samples were nasal secretions, sputa, tracheobronchial aspirate and bronchoalveolar lavage (Didier et al, 1996; del Aguila et al, 1997). Therapy suggested include, albendazole and fumagaline (Martı'nez-Giro'n et al, 2008).

This study aimed to evaluate the routine unit policy in starting with antibiotic treatment until sepsis could be ruled out; as all infants were $<16$ weeks of age and had respiratory distress among in-patients in Sohag University Hospitals.

\section{Subjects, Materials and Methods}

The study was applied on 21 infants ( 9 neonates and 12 infants $>28$ days) suffering from pneumonia who admitted into Sohag University Hospitals NICU \& PICU (neonatal \& pediatric intensive care units) in the period from July to December 2011. Sputum samples, before and after treatment was collected from patients. Each sample was divided into 2 parts; one was fixed and stained with Giemsa stain (Garcia and Bruckner 1993) and microscopically examined. The second was prepared for real time-PCR for Pneumocystis jirovecii. The routine antibiotic regimen was given $\left(3^{\text {rd }}\right.$ generation Cephalosporine and Ampicilline, Sulbactam).

Nine neonates with age ranged from 2-28 days $(16.6 \pm 9.1)$ and weight ranged from $2.5-4.5 \mathrm{~kg}$. $(3.311 \pm 0.752)$ and 12 infants with age ranged from 28 days-4 months $(53.3 \pm 24.2)$ and weight ranged from $1.750-4.8 \mathrm{~kg}$ (3.595 0.94) were recruited.

Pneumocystis jirovecii Real-TM/ PCR kits for the qualitative diagnosis were purchased (Space Biotechnologies). Primer: Taqman probes. DNA extraction kit was also purchased (Primerdesign). PCR procedure was carried out in the Standard Genetic Engineering and Molecular Biology Research Center, Assiut University. Sera were obtained, pre and post treatment for CRP (C reactive protein) as an indicative of the healing process. High sensitivity C-reactive protein ELISA kit (Diagnostics Biochemical Canada).

Statistical analysis: Data were comprised and analyzed using SPSS and Epi Info 6 programs. Student's $t$-test was used to determine a significant difference between two groups. A value of $P<0.05$ was considered statistically significant. 


\section{Results}

Among 21 patients suffering from pneumonia $12(57.1 \%)$ showed $P$. jirovecii in sputum samples (Fig. 1), 6 $(66.7 \%)$ were neonates $(6 / 9)$ and 6 $(50 \%)$ cases $(6 / 12)$ were infants with a significant difference $(\mathrm{p}=0.02)$.
With regression of symptoms, $P$. jirovecii disappeared in sputum of ten cases $(83.3 \%)$, with $\mathrm{P}$-value $=0.00,95.5 \%$ confidence, including all neonates and $4 / 6$ infants. Two patients $(16.7 \%)$ among the $P$. jirovecii pneumonic infants had Microspora species (Fig. 2) both improved at the end of treatment.

Table 1: Combined treatment on $P$. jirovecii:

\begin{tabular}{|c|c|c|}
\hline \multirow{2}{*}{ Patients } & \multicolumn{2}{|c|}{ P. jirovecii } \\
\cline { 2 - 3 } & Before & After \\
\hline Neonates $(\mathrm{n}=9)$ & $6=66.7 \% *(\mathrm{p}=0.02)$ & 0 \\
\hline Infants $(\mathrm{n}=12)$ & $6=50 \%$ & $2=16.7 \%$ \\
\hline Total & $12=57.1 \%$ & $2=9.5 \%$ \\
\hline
\end{tabular}

PCR was -ve in all cases before or after treatment. CRP level was elevated in 17 cases $(81 \%)$ of pneumonic infants ranged from 12 to172 $(70.5 \pm 49.1)$ before treatment and level decreased after treatment in 16 cases $(94 \%)$ and 8 (66.7\%) gave high CRP values (12 to172). All regressed to normal values except two as one had $P$. jirovecii and a neonate with a negative post treatment result.

\section{Discussion}

$P$. jirovecii is a worldwide cause of complicate pneumonia in the immunocompromized patients (Herraq et al, 2010). Diagnosis by many methods, among them Giemsa stain and real time PCR (Fillaux et al, 2008). Fujisawa et al. (2009) among HIV patients found positive rates of real time PCR and GMS stain were $20.3 \% \& 10.2 \%$ respectively $(\mathrm{P}<0.05)$ and considered the former one more specific. The present results showed higher rates with GMS stain (collectively, 14 cases in 42 samples $=33.3 \%$ ) but negative real time PCR. Many authors agreed with Fujisawa et al. (2009) in the superiority of real time PCR over other methods (Fillaux et al, 2008, Etoh, 2008; Fillaux et al, 2009), even Sun et al. (2009) stated that PCR assay seemed sensitive for the detection of $P$. jirovecii in the sputum specimens and could be used for screening PCP patients without HIV infection. However our results were against them as even when the organism was detected visually in the specimen (Fig.1) it was -ve in the PCR readings. This may be explained by gene mutation in $P$. jirovecii as suggested by Tyagi et al. (2010) and Harraq et al. (2010). Five to ten different genetic loci have been identified as potentially informative for molecular characterization and typing (Stringer, 1993; Lu et al, 1994). Concerning the typing that has actually been performed on human samples, the primary loci evaluated include: 1) a 346-bp region of mitochondrial large subunit rRNA gene mtlsrRNA (Wakefield et al, 1990) and 2) a 550-bp fragment containing the nuclear ribosomal internal transcribed spacer regions $1 \& 2$ (ITS1 and ITS2 ( Maini et al, 2013). When these 
loci are considered collectively, nucleotide variation can be detected at approximately 37 different positions. Genetic variation was also experienced in Portugol and Costa et al. (2006) suggested that DHFR (dihydrofolate reductase) gene polymorphisms are frequent in the Portuguese immunocompromised population.

Aly et al. (2008) reported that infant's pneumonia was mainly bacterial in origin, and patients reached NICU suffering from respiratory distress, most centers start their routine therapy with antibiotics. In the present study, although PCP was usually managed as Pyrgos et al. (2009) by pentamidine, atovaquone, clindamycin plus primaquine, and dapsone plus trimethoprim as alternatives, The antibiotic treatment used in our study succeeded in reaching a very satisfactory and significant results $(83.3 \%$ cure). To the best of the authors' knowledge, none has measured the effect of antibiotic combination on $P$. jirovecii hence no other results to compare. However, whether $P$. jirovecii was the causative organism or merely present due to the lowered immunity as a result of the existing pneumonia, the treatment resulted in its disappearance from the sputum.

Martı'nez-Giro'n (2008) reported that microspora are intracellular obligate parasites for respiratory transmission route. This was confirmed by the finding micro-organisms in the sputum and in tracheobronchial tree (Schwartz et al, 1992; Weber et al, 1993). The present two cases were successfully treated with albendazole and fumagaline (Martı'nez-Giro'n et al, 2008).
This improvement may be attributed to the general conditions of the patients and hence increasing their immunity.

\section{Conclusion}

The routine treatment for infant pneumonia was successful in microspora and $P$. jirovecii. Real time PCR failed to diagnose $P$. jirovecii local strain.

\section{References}

Aly HA, Badawy M, El-Kholy, Nabil, R, Mohamed A, 2008: Randomized, controlled trial on tracheal colonization of ventilated infants: Can gravity prevent ventilator-associated pneumonia? Pediatrics 122, 4:770-4.

Costa, MC, Esteves, F, Antunes, F, Matos, O, 2006: Genetic characterization of the dihydrofolate reductase gene of Pneumocystis jirovecii isolates from Portugal. J. Antimicrobial Chemother. 58, 6:1246-9.

del Aguila C, Lopez-Velez R, Fenoy S, et al, 1997: Identification of Enterocytozoon bieneusi spores in respiratory samples from an AIDS patient with a 2-year history of intestinal microsporidiosis. J. Clin. Microbiol. 35:1862-6.

Didier, E, Rogers, L, Orenstein, J, et al, 1996: Characterization of Encephalitozoon (septata) intestinalis isolates cultured from nasal mucosa \& bronchoalveolar lavage fluids of 2 AIDS patients. J. Eukaryot. Microbiol. 43:34-43.

Etoh, K, 2008: Evaluation of a realtime PCR assay for diagnosis of Pneumocystis pneumonia. Kurume Med. J. 55, 3/4:55-62.

Fillaux, J, Malvy, S, Alvarez, M, Fabre, R, Cassaing, S, et al, 2008: Accuracy of a routine real-time PCR assay for the diagnosis of Pneumocystis jiro- 
vecii pneumonia. J. Microbiol. Meth. 75, 2:258-61.

Franzen, C, Müller, A, Salzberger, B, Fätkenheuer, G, Diehl, V, et al, 1996: Chronic rhinosinusitis in patients with AIDS: potential role of microsporidia. AIDS 10:687-8.

Fujisawa, T, Suda, T, Matsuda, H, Inui, N, et al, 2009: Real-time PCR is more specific than conventional PCR for induced sputum diagnosis of Pneumocystis pneumonia in immunocompromised patients without HIV infection. Respirology 14, 2: 203-9.

Garcia, ER, Bruckner, DA, 1993: Diagnostic Medical Parasitology. American Microbiology Society, Washington, DC.

Herraq M, Elfassy-Fihry MT, Alaoui, YA, 2010: Pneumocystis jirovecii: What does this mean? Rev. Pneumol. Clin. 66, 6:342-6.

Kordek, A, Kołodziejczyk, L, Adam, M, Skotarczak, B, Loniewska, B, et al, 2007: Prematurity and protracted mechanical ventilation as risk factors for Pneumocystis jiroveci in HIV-negative neonates in an intensive care unit. Turk. J. Pediatr. 49, 2:158-64.

Kordek, A, Kołodziejczyk, L, Pawlus, B, Loniewska, B, Kuźna, W, et al, 2006: Pneumocystis pneumonia in newborns: a challenge in contemporary intensive care. Ann. Acad. Med. Stetin. 52, 2:65-70.

Lu, JJ, Chen, C, Bartlett, M, Smith, J, Lee, C, 1995: Comparison of six different PCR methods for detection of Pneumocystis carinii. J. Clin. Microbiol. 33:2785-8.

Maini, R, Henderson, KL, Sheridan, EA, Lamagni, T, Nichols G, Delpech,
V, et al, 2013: Increasing Pneumocystis Pneumonia, England, UK, 20002010. Emerg. Infect. Dis. 19, 3:386-92. Martı'nez-Giro'n, R, Esteban JG, Ribas A, Doganci L, 2008: Protozoa in respiratory pathology: a review Eur. Respir. J. 32:1354-70

Pyrgos, V, Shoham, S, Roilides, E, Walsh, TJ, 2009: Pneumocystis pneumonia in children. Paediatr. Respir. Rev. 10, 4:192-8.

Sage, EK, Noursadeghi, M, Evans, HE, Parker, SJ, Copas, AJ, et al, 2010: Prognostic value of $C$-reactive protein in HIV-infected patients with Pneumocystis jirovecii pneumonia. Int. J. STD/AIDS 21, 4:288-92

Schwartz, DA, Bryan, RT, HewanLowe, KO, et al, 1992: Disseminated microsporidiosis (Encephalitozoon hellem) and acquired immunodeficiency syndrome: Autopsy evidence for respiratory acquisition. Arch. Pathol. Lab. Med. 116:660-8.

Shankar, SM, Nania, JJ, 2007: Management of Pneumocystis jiroveci pneumonia in children receiving chemotherapy. Paediatr. Drugs 9, 5:301-9.

Stringer, JR, 1993: Identity of Pneumocystis carinii: not a single protozoan, but a diverse group of exotic fungi. Infect. Agents Dis. 2:109-17.

Sun, L, Huang, MJ, An, YJ, Guo, Z Z, 2009: An epidemiologic study on Pneumocystis pneumonia in non-HIV infected patients in China. Zhonghua Liu Xing Bing Xue Za Zhi. 30, 4:34851.

Tyagi, AK, Mirdha, BR, Luthra, K, Guleria, R, Mohan, A, et al, 2010: Dihydropteroate synthase (DHPS) gene 
mutation study in HIV-infected Indian patients with Pneumocystis jirovecii pneumonia. J. Infect. Dev. Ctries. 24, 11:761-6.

Wakefield, AE, Pixley, FJ, Banerji, S, Sinclair, K, Miller, RF, et al, 1990: Detection of Pneumocystis carinii with DNA amplification. Lancet 336:451-3.
Weber, R, Kuster, H, Visvesvara, GS, Bryan, RT, Schwartz, DA, et al, 1993: Disseminated microsporidiosis due to Encephalitozoon hellem: Pulmonary colonization, microhematuria, and mild conjunctivitis in a patient with AIDS. Clin. Infect. Dis. 17:415-9.

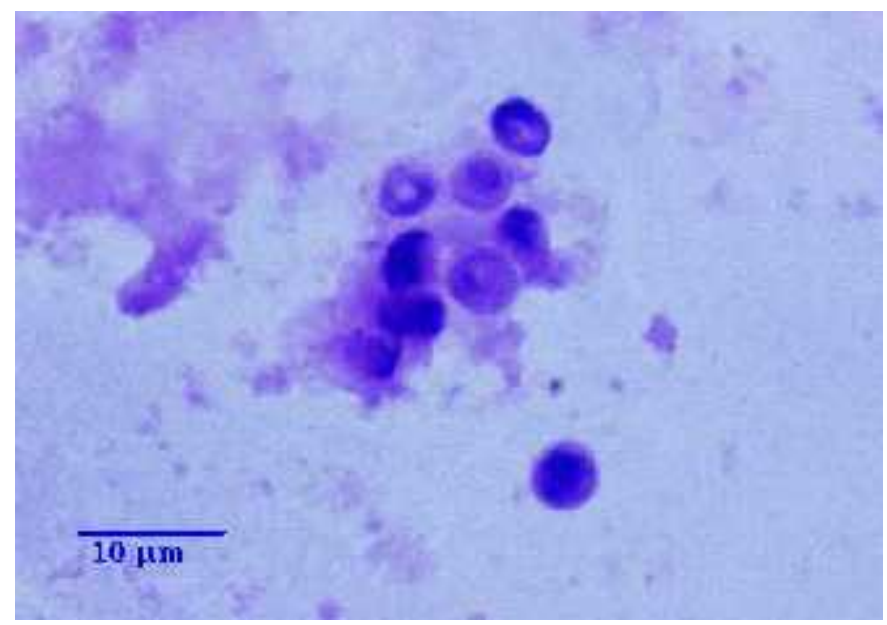

Fig1: Pneumocystis jirovecii in sputum sample, Geimsa stain x 200.

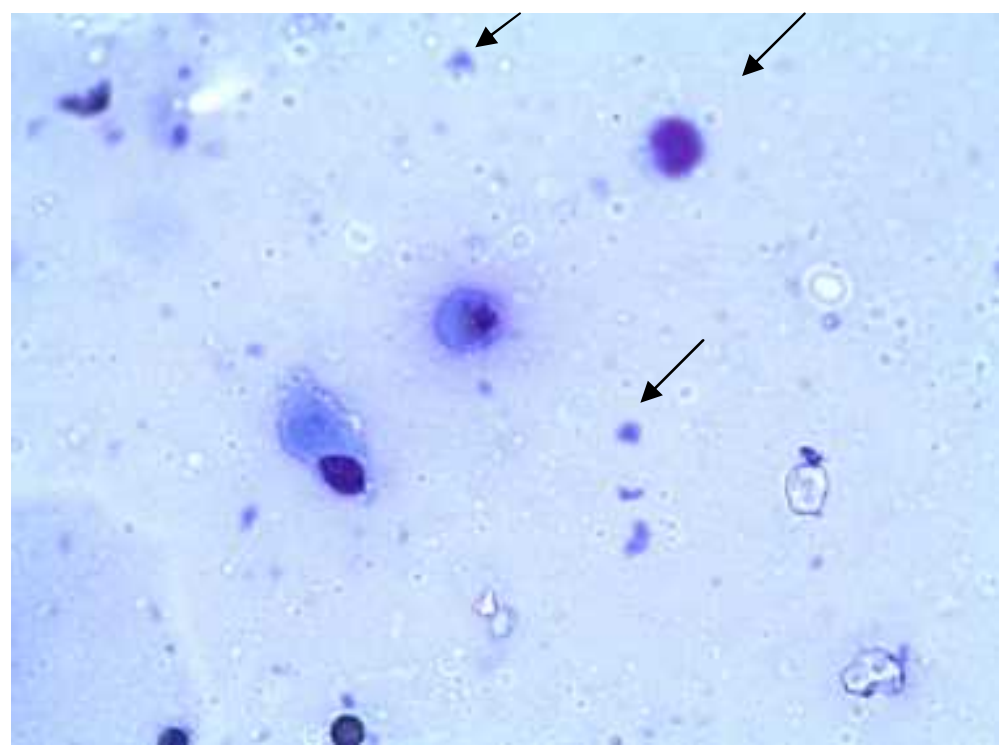

Fig 2: Intra and extracellular Microspora in sputum sample, Geimsa stain x100 